\title{
PESTICIDE RESIDUES AS ENVIRONMETAL CONTAMINANTS IN FOODS IN NEPAL
}

\author{
Pramod Koirala, MSc. Nutrition ${ }^{14}$ \\ Dambar B. Khadka, B. Tech. Food ${ }^{15}$ \\ Arunananda Mishra, MSc. Food Tech. ${ }^{16}$
}

\begin{abstract}
This paper reviews the occurrence of pesticides in foods in Nepal during 1995-2004. A total of one thousand and thirty four samples of different food commodities were analyzed for detection of organochlorines (DDT, BHC) and organophosphorus (malathion, parathion, methyl parathion) pesticides. Among all samples analysed $12 \%$ samples were detected with the residues of pesticides which included Malathion (3.9\%), BHC (3.1\%), Methyl parathion (2.8\%), DDT (1.8\%) and Parathion (0.3\%). Commoditywise detection of pesticide residues showed the highest level of contamination in root vegetables (11.9\%) followed by leaf vegetables (10.9\%). Therefore, there is a threat of pesticide residues in foods and may endanger to public health. Government efforts to control misuse of pesticides is not sufficient, therefore, the concerned stakeholders have the shared responsibility to solve it. There is a good scope of working with appropriate intervention measures in this area for NGOs, INGOs, academic institution to prevent the pesticide pollution in food.
\end{abstract}

Key words: Pesticides, Foods, Residue

Introduction

Pesticides being toxic in nature do not differentiate between targeted and non-targeted species and threaten the health and well-being of human and wildlife in every region of the world (Wassemann, 1972). These highly stable compounds can last for years and decades before breaking down in the environment. They circulate globally and persistent pesticides released in one part of the world can, through a repeated process of evaporation and deposit, be transported through the atmosphere to regions far away from the original source (Williams, 2000).

Most of the pesticides released into the environment every year by human activity and are among the most dangerous. They are highly toxic, causing the number of adverse effects, notably death, diseases and birth defects among human and animals. Specific effect can include cancer, allergies and hypersensitivity, damage to the central and peripheral nervous systems, reproductive disorders, and disruption of the immune system (Strecct 1981, Maroni, 1990).

Current projections foresee that farmers in developing countries will steadily increase their reliance on pesticides as a major means of increasing their harvests (Palikhe, 2001). FAO's study agriculture toward 2000 projects annual growth in pesticide use in developing countries at 4.5 percent until the end of the century (Dahal, 1995).

In 1955, DDT was the first pesticide imported in Nepal and then BHC. Since 1960s the organophosphorus group of pesticides was introduced. Different pesticides of this group like methyl parathion, malathion slowly gained their markets replacing the monopoly markets and use of BHC and other organochroine pesticides (Karlman, 1987). In Nepal, import and distribution of pesticides has been channalized in three routes a) ministry of health: for the

14 Food Research Officer, Email: pramodkoirala2002@yahoo.com,

15 Food Inspector, Email: damodarkhakdadftqc@gmail.com

16 DDG, Department of Food Technology and Quality Control, Babarmahal, Email: dftqc@mail.com 
purpose of controlling vector borne diseases b) through Agriculture Inputs Corporation, c) Private dealers and distributors (Giri, 1998).

\section{Materials and Methods}

Samples were collected from the local market of district head-quarter of Nepal and were purposive samplings. Foods liable to pesticide use were targeted to sampling purpose and collected from local market of different districts. Food Inspectors of DFTQC collected the all samples in interval of 1994 to 2004. A total of one thousand and thirty four samples were received in the laboratory during 1995-2004 for the detection and estimation of organochorine (DDT, BHC) and organophosphorus (malathion, parathion, methyl parathion). Thin layer chromatographic technique was used for the detection and estimation of pesticides residues.

\section{Results and Discussions}

A total of one thousand and thirty four samples were analysed for the following type of foods given in figure one.

Table 1 Year-wise sample analysis and detection of pesticides

\begin{tabular}{|c|c|c|c|c|c|c|}
\hline Year & No of samples & DDT & $\mathrm{BHC}$ & Malathion & Parathion & $\begin{array}{l}\text { Methyl } \\
\text { Parathion }\end{array}$ \\
\hline 1995 & 34 & 2 & 13 & 10 & 4 & 3 \\
\hline 1996 & 64 & & & 7 & & 2 \\
\hline 1997 & 121 & & & 1 & & 10 \\
\hline 1998 & 112 & & & 5 & & 8 \\
\hline 1999 & 70 & & & 8 & & 4 \\
\hline 2000 & 54 & & 1 & 10 & & \\
\hline 2001 & 134 & 17 & 17 & & & 2 \\
\hline 2002 & 106 & & & & & \\
\hline 2003 & 36 & & & & & \\
\hline 2004 & 303 & & 2 & & & \\
\hline Total & 1034 & 19 & 33 & 41 & 4 & 29 \\
\hline
\end{tabular}

Source : Annual Bulletin, 1995-2004, DFTQC (Data Compilation). 
Fig 1 Type of samples analysed for pesticides.

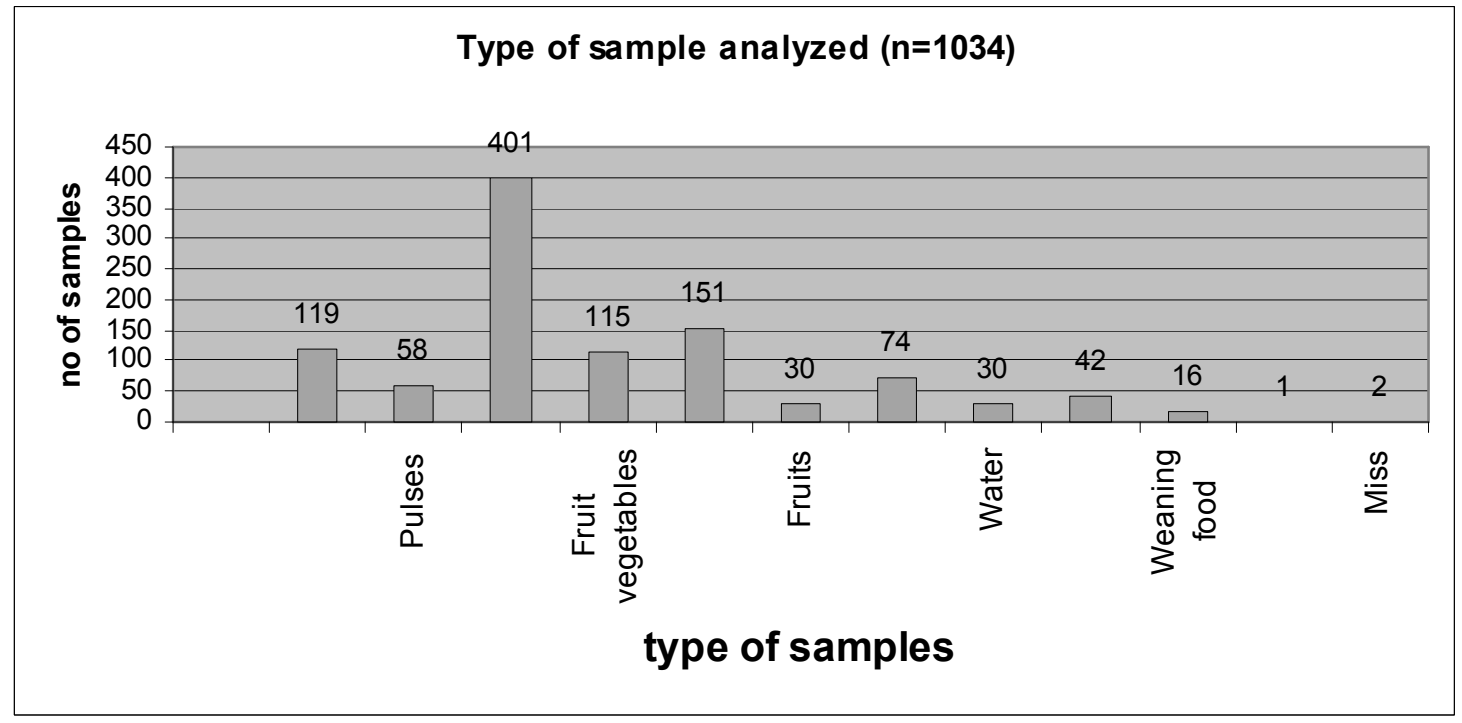

Fig 2 Pesticides contamination in food samples

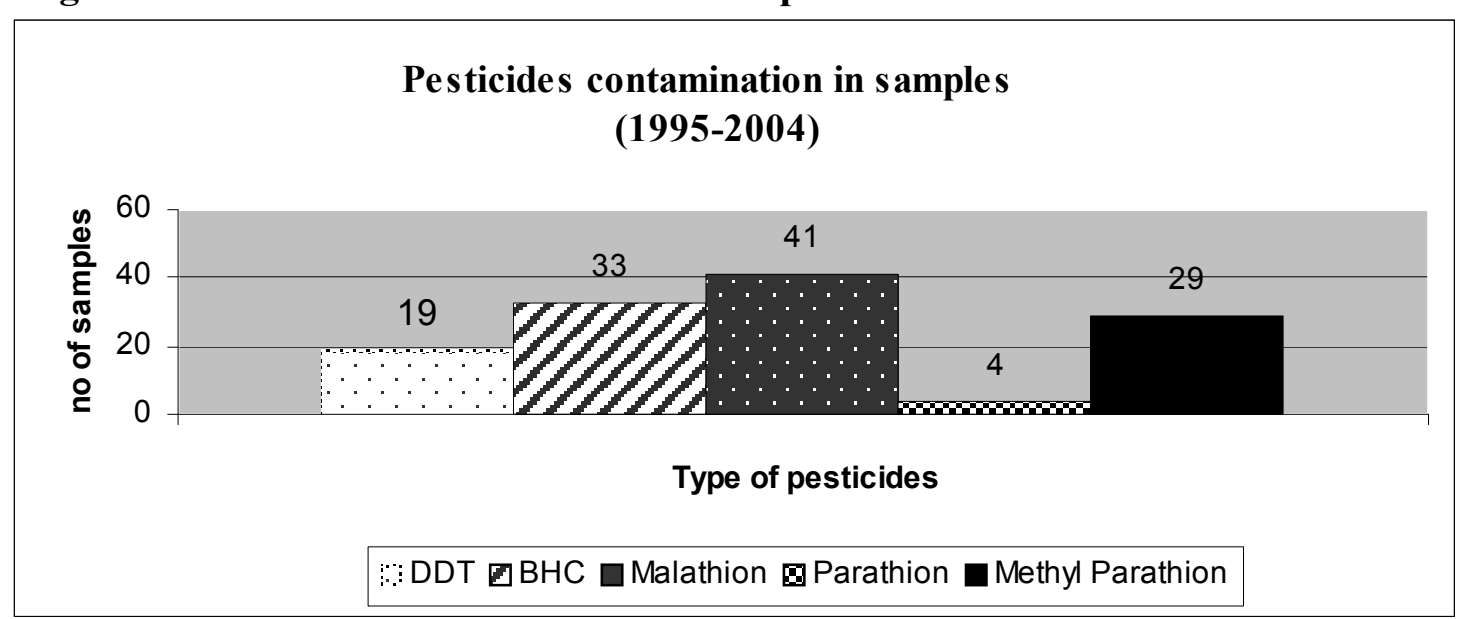

Among all samples analysed $(12.1 \%)$ of the total samples were detected with the residues of pesticides, which included malathion (3.9\%), BHC (3.1\%), Methyl parathion (2.8\%), DDT(1.8\%) and parathion $(0.3 \%)$. Commodity-wise detection of pesticide residues showed highest level of contamination in root vegetables $(11.9 \%)$ followed by root vegetables $(10.9 \%)$. The number and type and range of pesticides detected in a particular food group is given below in table two. 
Table 2 Food Group and Range of pesticides detected

\begin{tabular}{|c|c|c|c|c|c|c|c|c|c|c|c|}
\hline \multirow[t]{2}{*}{ Type of foods } & \multirow{2}{*}{$\begin{array}{l}\text { No of } \\
\text { samples }\end{array}$} & \multicolumn{2}{|c|}{ DDT } & \multicolumn{2}{|c|}{ BHC } & \multicolumn{2}{|c|}{ Malathion } & \multicolumn{2}{|c|}{ Parathion } & \multicolumn{2}{|c|}{ Methyl Parathion } \\
\hline & & Detected & Range & Detected & Range & Detected & Range & Detected & Range & Detected & Range \\
\hline Cereals & 119 & & & 2 & *Tr-1 & 4 & $01-4$ & 1 & 2.5 & & \\
\hline Pulses & 58 & & & & & 4 & *Tr-8 & & & & \\
\hline Leaf vegetables & 401 & & & 4 & *Tr-8 & 20 & *Tr-2.66 & & & 20 & $*$ Tr-4 \\
\hline Fruit vegetables & 115 & & & 1 & $* \mathrm{Tr}$ & 6 & *Tr-1.6 & & & 3 & $\begin{array}{l}* \mathrm{Tr}- \\
2.66\end{array}$ \\
\hline Root vegetables & 151 & 17 & $\begin{array}{l}* \text { Tr- } \\
1.33\end{array}$ & 17 & $\begin{array}{l}* \mathrm{Tr}- \\
9.99 \\
\end{array}$ & & & & & 1 & 2.66 \\
\hline Fruits & 30 & & & & & 1 & 0.4 & & & 2 & $0.4-0.8$ \\
\hline Tea & 74 & 1 & 0.2 & 9 & $\begin{array}{c}\text { *Tr- } \\
1.4\end{array}$ & 6 & $0.2-10$ & 3 & $0.2-2.5$ & 3 & $0.2-2.5$ \\
\hline Water & 30 & & & & & & & & & & \\
\hline soft drinks & 42 & & & & & & & & & & \\
\hline Weaning food & 16 & & & & & & & & & & \\
\hline Milk & 1 & 1 & $* \operatorname{Tr}$ & & & & & & & & \\
\hline Miss & 2 & & & & & & & & & & \\
\hline Total & 1034 & 19 & & 33 & & 41 & & 4 & & 29 & \\
\hline
\end{tabular}

Source : Annual Bulletin, 1995-2004, DFTQC (Data Compilation).

Among the DDT identified food samples, nearly ninety percent samples of root vegetables were found contaminated whereas one sample each of milk and tea were also with traces of DDT. Similarly, among BHC noticed samples, it was observed more than a half $(51.1 \%)$ of the samples of root vegetables followed by fruits $(26.4 \%)$ and then leaf vegetables, cereals and fruit vegetables. Among those with malathion detected, it was the highest among the samples of leaf vegetables $(48.7 \%)$ followed by tea $(14.6 \%)$. The residue of malathion observed was the highest in the samples of tea (up to $10 \mathrm{ppm}$ ). Parathion detected in only four samples and methyl parathion detected in twenty nine samples. Methyl parathion detected highest in samples of leaf vegetables $68.9 \%$.

\section{Conclusion and Recommendations}

Contamination of food with pesticide and their degradation products is of great concern to every one due to their health hazards. The use of pesticide for the content of pests in agriculture and storage is quite indispensable. The indiscriminant use of pesticide in agriculture and storage has resulted higher amount of residues in foods. There is an increased risk of pesticides in foods as the residues of pesticides are detected in a variety of foods. Residues of pesticides were found higher in vegetables than other foods. At the same time, consumption of vegetables is high as it provides nutrients especially vitamins and minerals.

Despite the government efforts to discourage misuse of pesticides, a little bit progress has only been made so far. Therefore, there is a need of combined and coordinated efforts of all the stakeholders associated with it. Agencies including governments and other than governments, such as NGOs, INGOs, academic institution with a suitable intervention program 
will help to solve it. Appropriate awareness campaign at all levels might help to prevent the problems.

\section{REFERENCES}

1. CFRL, 1995/1996: "Pesticide Residue: Laboratory Investigation", Annual Bulletin, Central Food Research Laboratory, HMGN/Ministry of Agriculture, pp.20-23.

2. CFRL, 1996/1997: "Study of Investigative samples: Pesticide Residue", Annual Bulletin, Central Food Research Laboratory HMGN/Ministry of Agriculture, pp.18-20.

3. CFRL, 1998/1999: "Food Contaminants: Pesticide Residue", Annual Bulletin, Central Food Research Laboratory, HMGN/Ministry of Agriculture, pp.29.

4. CFRL, 1999/2000: "Analysis Reports: Pesticide Residue", Annual Bulletin, Central Food Research Laboratory, HMGN/Ministry of Agriculture, pp. 47-48.

5. DFTQC, 2000/2001: "Food Contaminants Reports: Pesticide Residue", Annual Bulletin, HMGN/Ministry of Agriculture, pp. 73-74.

6. DFTQC, 2001/2002: "Food Contaminants Reports: Pesticide Residue", Annual Bulletin, HMGN/Ministry of Agriculture, pp. 35

7. DFTQC, 2002/2003: "Contaminants: Pesticide Residue", Annual Bulletin, HMGN/Ministry of Agriculture, pp. 34

8. DFTQC, 2003/2004: "Contaminants: Pesticide Residue", Annual Bulletin, HMGN/Ministry of Agriculture, pp. 24-25.

9. Dahal, L., Baker, S.L., and Gyawali, B.K., 1995: "Promoting Proper Use of Pesticides use in Nepal", HMG/Ministry of Agriculture/Winrock International, NEPAL

10. Giri Neeru, P., 1998: "PESTICIDES POLLUTION IN VEGETABLE CROP IN KATHMANDU VALLEY", MSC THESIS, DEPARTMENT OF ZOOLOGY, TRIBHUVAN UNIVERSITY, NEPAL

11. Klarman, Williams, L., 1987:" Pesticide use in Nepal", AREP consultancy report no 9 Winrock International Institute for Agriculture Development and USAID, Nepal

12. Maroni, H. M., 1990: " Studying the effects of pesticides on humans (International Commission on Occupational Health)", Proceedings of the 9th International workshop, International Centre for Pesticide Safety, Busto Garolfo, Milan, Italy. ICOH, Geneva, Switzerland; 2-4 May 1990

13. Palikhe, B.R., 2001: "Pesticides pollution management in Nepal: In harmony with nature", Agriculture and Environment communication issue, Ministry of Agriculture and Cooperative, Kathmandu, Nepal

14. Strecct, J.C., 1981: Pesticide and the immune system, In Immunologic considerations in Toxicology, Vol 1 Ed Sharma RP, CRC Press

15. Williams Michael, 2000:" Nutrition and the Environment", ACC SCN 21 Report, Geneva Switzerland

16. Wassemann, M., and Wasserman, D., 1972: Effects of Organochorine insecticides on homeostatic and immunologic process, fate of pesticides in the environment ,Gordon and Breach London 